\title{
Regression model of the influence of the height of drum mixer blades on the quality of mixture
}

\author{
Konstantin Fudin ${ }^{1, *}$, Vladimir Konovalov ${ }^{1}$, Vladimir Zaitsev $^{1}$, and Vyacheslav Teryushkov ${ }^{2}$ \\ ${ }^{1}$ Penza State Technological University, 1A/11, Proezd Baydukova / Gagarina Street, 440039, Penza, \\ Russia \\ ${ }^{2}$ Penza State Agrarian University, 30, Botanicheskaya Street, 440014, Penza, Russia
}

\begin{abstract}
The aim of the research was to establish the influence of the number and height of blades of a drum mixer on the quality of the prepared mixture of concentrated feed. The research method of the drum mixer provided for the experimental determination of the coefficient of variation (unevenness) of the mixture with a three-level combination of the blades height and their number. The absence of an extremum according to the obtained data required the use of a fourth level of the number of blades. Computer processing of the results made it possible to establish a functional dependence of the influence of design factors on the quality of the mixture. The implementation of the used research methodology for the operation of the drum mixer made it possible to establish an adequate functional dependence of the influence of the number of blades and their height on the quality of the mixture. The number of blades used practically does not affect the coefficient of variation of the content of the control component. The values change less than experimental error. However, existing trends indicate a slight (about 1\%) decrease in the coefficient of variation of the mixture with an increase in the number of blades from 2 to 8 pcs. For $50 \mathrm{~kg}$ of feed in a drum capacity of $0.26 \mathrm{~m} 3$, the height of the blades is about 0.15 $\mathrm{m}$. The increase or decrease in the height to $0.125 \mathrm{~m}$ or $0.175 \mathrm{~m}$ affects the quality of the mixture, increasing the coefficient of variation from $20.6 \%$ to $34-50 \%$ at the proportion of the control component of $1 \%$ and the mixing time of 200 seconds.
\end{abstract}

\section{Introduction}

Approximately one third of the cost of livestock production consists of the cost of feed and its preparation. It is possible to increase the efficiency of the spent funds through the use of high-quality feed and reduce the cost of depreciation and operation of the technical equipment used. Accordingly, the technology used for the preparation of feed should allow producing complete feed mixtures, and the equipment used should have a low cost. It is possible to solve this task for small livestock production when its own feed grain and purchased concentrated pre-mixes with all the necessary set of substances needed by animals are used. The issue of preparing high-quality mixtures in the economy is decided by the use of a mixer. It is important to choose mixer type and purchase it at a suitable price.

* Corresponding author: kpfudin@yandex.ru 
In recent years, mixers with a fixed tank and a working body located inside in the form of a paddle mixer [1, 2, 3], auger [4, 5], a tape spiral [6], a disk rotor [7], etc are used most often. A working body used is not only vertical, but also horizontal [2].

Unfortunately, these working bodies for batch mixers are energy-consuming. Circulation mixers are more often used for the preparation of liquid mixtures, but are also energyconsuming $[8,9]$.

Continuous mixers [10] consume significantly less energy, but strict compliance with the recipe is problematic for them. In addition to scales, they also require the cost of acquiring complex continuous proportioning plants. Therefore, batch mixers should be used for small livestock farms $[2,11,12]$.

Among batch mixers, mixers with an inclined rotating tank with and without blades [1315], including concrete mixers, are energy efficient. They are made both on the basis of a car [16], and mobile electrified structures [17] with manual movement to the place of use from vehicles. Such devices manufactured by the industry are widely represented in retail chains and have low cost. Unfortunately, their working bodies are optimized for building mixtures with a high density of components $[17,18]$. To prepare feed mixtures in small livestock facilities, the working bodies require modernization [19].

In the process of researching mixers, various aspects of their work are studied. Most often, the influence of structural and kinematic parameters on the non-uniformity (coefficient of variation) of a mixture [18] and energy consumption [20] is investigated. Due to the differences in the physicomechanical properties of the raw materials, the ratio of components and design features of the working bodies, the quality indicators change significantly. Therefore, they require refinement for different conditions of preparation of the mixture. When describing the function of changing the quality of a mixture, a number of authors [2] recommend the use of an exponential function.

The aim of the research was to establish the influence of the number and height of the blades of the drum mixer on the quality of the prepared mixture of concentrated feed.

\section{Methods and Materials}

The experimental research methodology provided for the installation of replaceable working bodies (L-shaped blades) on the inner surface of the rotating drum of the mixer, differing in number and height; determination of the quality of the prepared mixture and statistical analysis of the results. Moreover, the number of installed blades in the experiments corresponded to 2, 4, 6 and 8 pcs. The height of the blades was $0.125 \mathrm{~mm}, 0.150 \mathrm{~mm}$ and $0.175 \mathrm{~mm}$. The quality of the mixture was determined as the coefficient of variation of the number of barley grains in groats for 20 samples. The density of the prepared mixture was about $620 \mathrm{~kg} / \mathrm{m}^{3}$.

A mobile concrete mixer (see Fig. 1) with a hopper volume of 260 liters and a rotation speed of 28 revolutions per minute was used as a basic mixer. The angle of the axis of rotation of the drum was set 15 degrees from the horizon. When preparing the mixture, groats of fillers were first loaded into the rotating hopper of the mixer, and then the control component. $1 \%$ of the control component was added. After the mixing time, the mixer stopped, and samples weighing 100 grams were taken. As a result of processing the results obtained by the Statistika and MathCAD programs, a regression model was obtained and evaluated by statistical criteria. Based on a graphical analysis, a search for the zone of optimal values of the height of the blades and their rational number was made.

During the experiments, the mixing time was 120,180 and 300 seconds. The average mixing time of the components was $200 \mathrm{~s}$. For each mixing duration, 3 values of the coefficient of variation were determined (i.e., there were three replications of the experiment). Variations in the coefficient of variation were $\pm 2-3 \%$. Therefore, in order to 
find the arithmetic mean value for specific angles of installation of the blades the data for all time intervals were used. Arithmetic mean values were used for regression analysis of the experimental results.

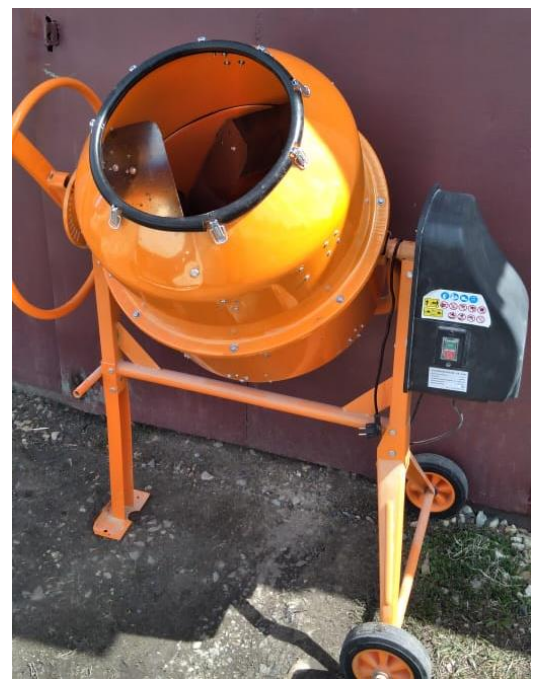

Fig. 1. The exterior of the investigated drum mixer for loose components of the mixture with the investigated blades.

\section{Experiment and calculations}

The above review analysis showed that the quality of the mixture (coefficient of variation of the content of the control component in the samples: $v, \%$ ) should be described by the exponential expression [2]:

$$
v=100 \cdot \exp (-k \cdot T)
$$

The exponent $(-k \cdot T)$ is denoted by $w$, i.e.:

$$
w=-k \cdot T^{\prime},
$$

where $k$ - 'the empirical indicator of the intensity of mixing of the working body; $T$ ' - the duration of mixing the components (average).

For regression processing of the results, we recalculated the initial experimental data by obtaining the natural logarithm of the values of the coefficient of variation $(0.01 \%)$. After processing the obtained data, a model expression of the exponent was obtained (Fig. 2, 3):

$$
\begin{aligned}
& w=-1.3975+(-8.42566+27.194 \cdot h+0.63895 / h) \times \\
& \times(1.968438-0.02418 \cdot \mathrm{z}+0.20674 / \mathrm{z})-0.02463 \cdot \mathrm{z} \cdot \mathrm{h} .
\end{aligned}
$$

The values of the statistical criteria $F_{\text {test }}=0.999252$ and the Pearson correlation coefficient $R=0.999711$ indicate the adequacy of the obtained model. This is confirmed by both the location of residues not taken into account by the model (Figure 4) and the convergence of the calculated values with the experimental data (Figure 5).

Taking into account that the degree of exponential function includes mixing time, it is possible to calculate an empirical indicator of the intensity of mixing of the working body: 


$$
k=\frac{w}{T}
$$

For the investigated version of the working body of the mixer, the expression of an empirical indicator of the intensity of mixing of the working body is:

$$
\begin{gathered}
k=-k_{1} \cdot\{-0.007+(-8.42566+27.194 \cdot h+0.63895 / h) \times \\
\times(1.968438-0.02418 \cdot \mathrm{z}+0.20674 / \mathrm{z}) / 200-0.000123 \cdot \mathrm{z} \cdot \mathrm{h}\} .
\end{gathered}
$$

where $k_{1}$ - the empirical coefficient of the influence of the duration of mixing on the quality of the mixture; in this case $-k_{1}=1$.

Graphic results of both the exponent and the empirical indicator of mixing intensity are presented in Figures 6 and 7.

After implementing the numerical model by the MathCAD program, a graphic image of the change in the mixture non-uniformity depending on the number and height of the blades was obtained (Figure 8).

Analyzing the results, we see that the number of blades has a slight effect on the results of the research. The impact of this factor is less than the experimental error. Nevertheless, with an increase in the number of blades of the structure used, the quality of the mixture of concentrated feed with a density of $620 \mathrm{~kg} / \mathrm{m} 3$ improves, but not significantly. This is apparently affected by a similar process of material circulation. The circulation of material across the axis of rotation is carried out regardless of the presence of blades or their absence. The increase in the number of blades slightly increases the turbulization of the material and, thereby, improves the quality of the mixture.

\section{Model: $w=a 00+\left(a 0+a 1^{*} h+a 2 / h\right)^{*}\left(b 0+b 1^{*} n+b 2 / n\right)+a 12^{*} h^{*} n$ $w=-1,3975+\left(-8,425656+27,194^{*} \mathrm{~h}+0,63895 / \mathrm{h}\right)^{*}$ *(1,968437-0,0241765*z-0,2067445/z)-0,0246*h*z}
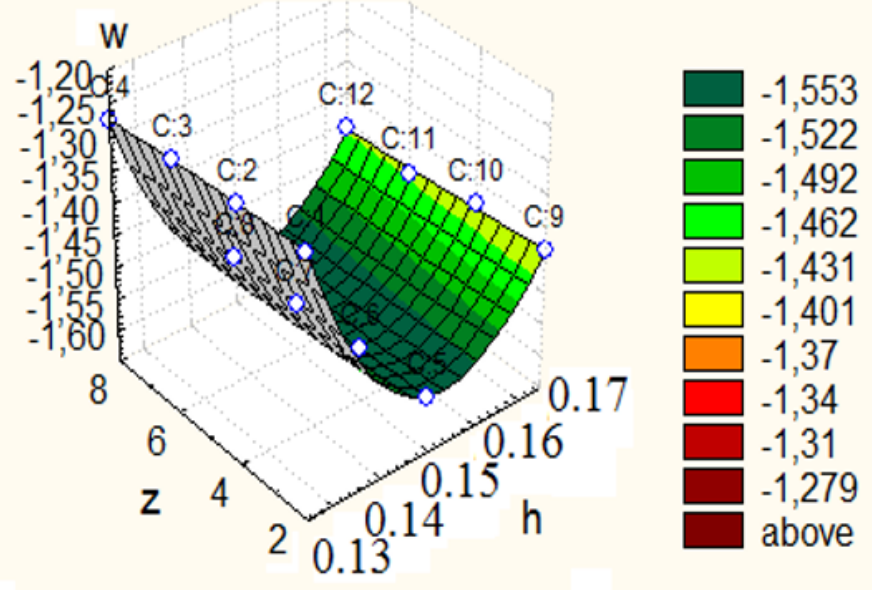

Fig. 2. Spatial graphic representation of the statistical model of the exponent $w$ of the expression of the quality of the mixture from the number of blades $\mathrm{Z}$ (pcs.) and the height of the blades $\mathrm{h}(\mathrm{m})$. 


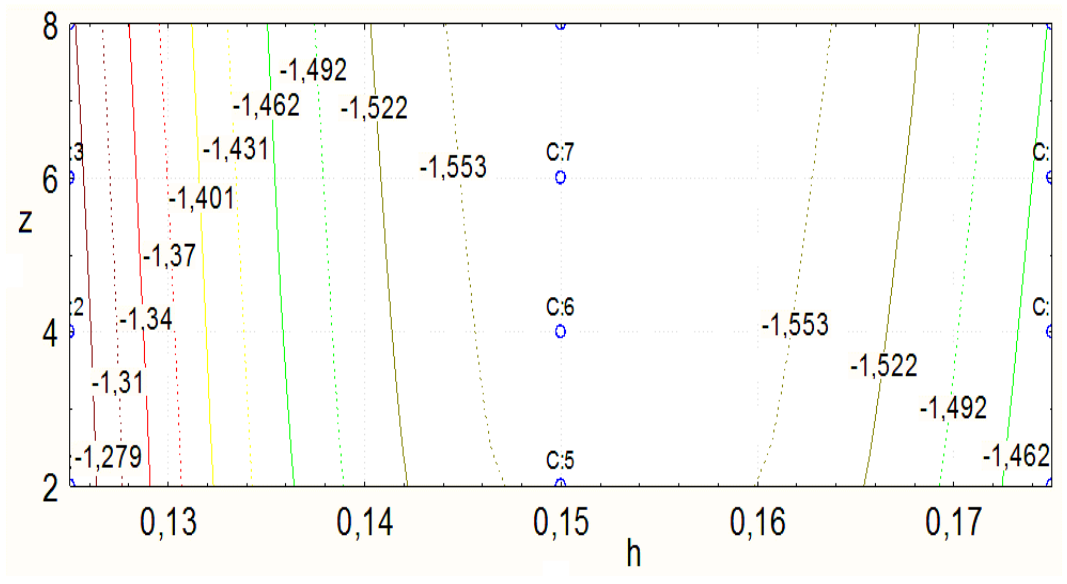

Fig. 3. Two-dimensional graphic representation of a statistical model of the exponent $w$ of the expression of the quality of the mixture from the height of the blades $h(m)$ and their number $\mathrm{Z}$ (pcs.).

The height of the blades changes the quality of the mixture more intensively. High blades are able to capture almost the entire height of the mixed concentrated feed. As a result, the entire amount of feed in the cross section is poured. That is, mixing occurs inside the material from the layer in cross section across the axis of rotation of the drum. With small blades, only a small part of the material rises and it is poured from above onto the remaining part of the feed at the bottom. In this case, the feed on the blades is shifted to the outlet of the drum due to the longitudinal inclination of the radially arranged blades, and the feed at the bottom is poured into the lower part of the drum (moving away from the loading hole). As the height of the blades changes, the shift of the feed layers along the rotation axis will vary. The most preferred proportions for $50 \mathrm{~kg}$ of feed is provided by the height of the blades of about 0.15 $\mathrm{m}$. Both an increase in the height of the blades and their decrease affects the quality of the feed.

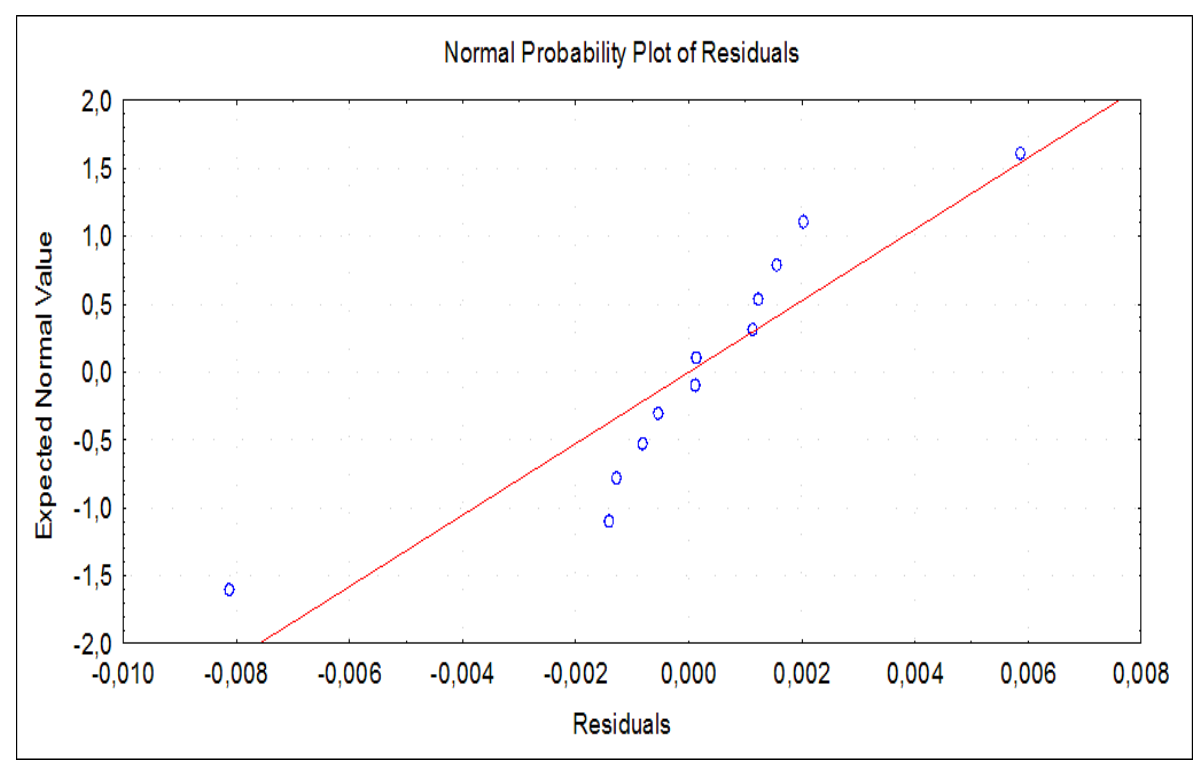

Fig. 4. The location chart of residues not considered by the model. 
Observed versus Predicted Values

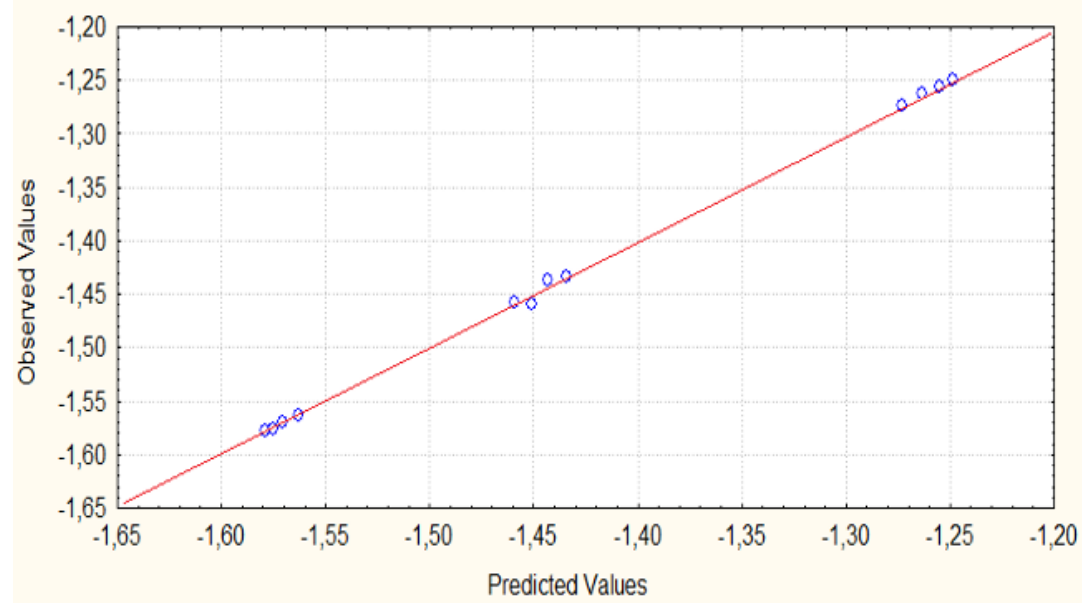

Fig. 5. The convergence graph of calculated values $w$ with the experimental data.

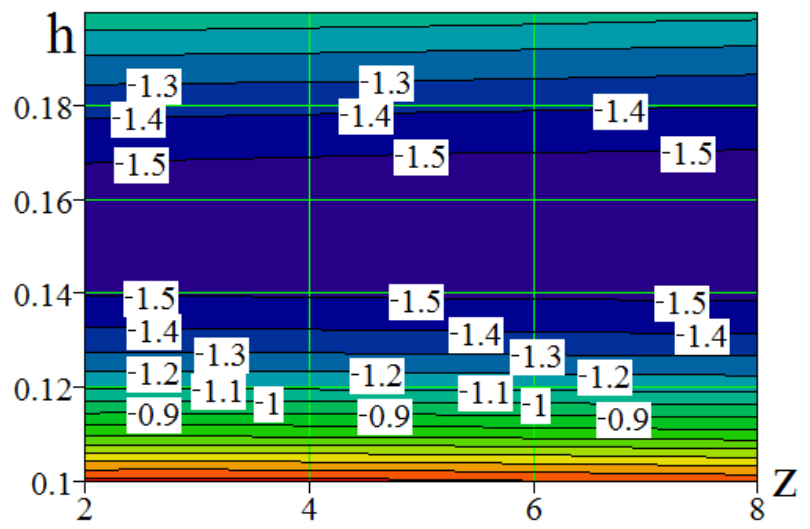

Fig. 6. A two-dimensional graphic representation of a statistical model of the exponent $w$ of the expression of the quality of the mixture as a function of quantity $\mathrm{Z}$ (pcs.) and blade height $\mathrm{h}(\mathrm{m})$.

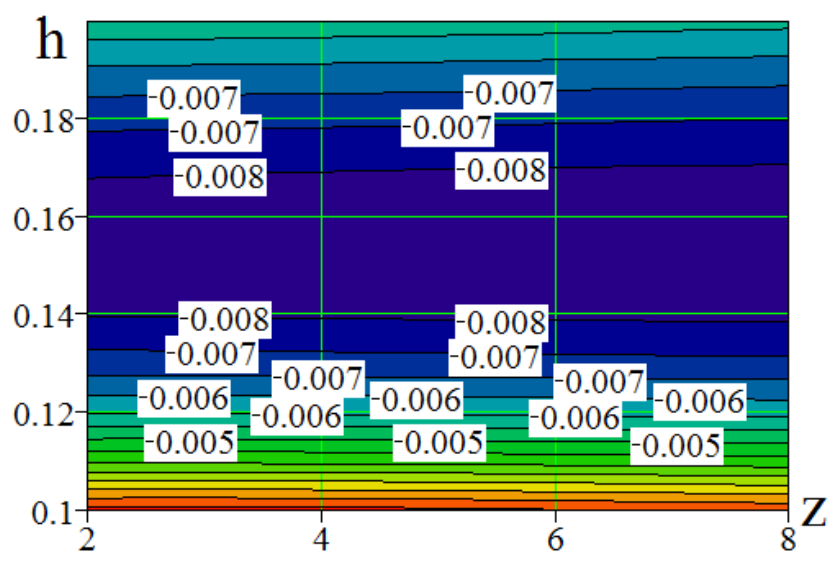

Fig. 7. A two-dimensional graphic representation of a statistical model of an empirical indicator of mixing intensity of a working body $(-\mathrm{k})$ expressing the quality of a mixture as a function of quantity $\mathrm{Z}$ (pcs.) and blade height $\mathrm{h}(\mathrm{m})$. 


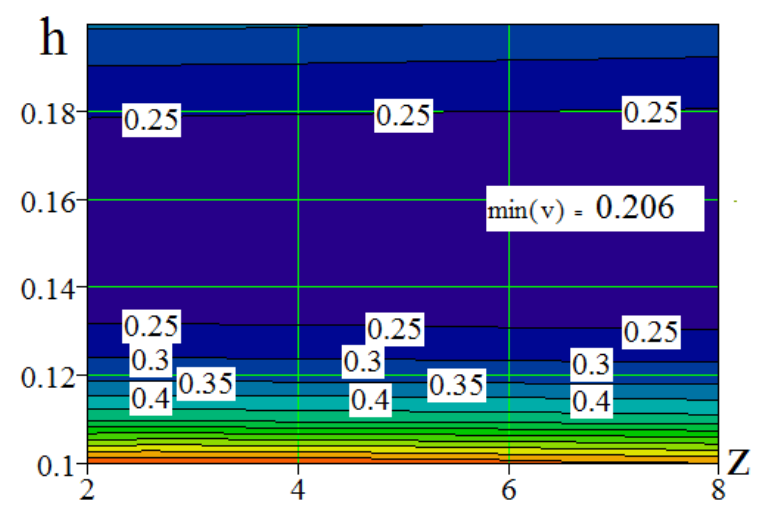

Fig. 8. A two-dimensional graphic representation of a statistical model of an indicator of the degree of expression of a mixture's quality from the quantity Z (pcs.) and blade height $h(\mathrm{~m})$.

\section{Conclusion}

The implementation of the used research methodology on the operation of the drum mixer made it possible to establish an adequate functional dependence of the influence of the number of blades and their height on the quality of the mixture. The number of blades practically does not affect the coefficient of variation of the content of the control component. Values change less than experimental error. However, existing trends indicate a slight (about $1 \%$ ) decrease in the coefficient of variation of the mixture with an increase in the number of blades from 2 to 8 pcs. For $50 \mathrm{~kg}$ of feed in a drum container with a volume of $0.26 \mathrm{~m}^{3}$, the height of the blades is about $0.15 \mathrm{~m}$. The increase or decrease to $0.125 \mathrm{~m}$ or $0.175 \mathrm{~m}$ affects the quality of the mixture, increasing the coefficient of variation from $20.6 \%$ to $34-50 \%$ with a share of the control component of $1 \%$ and the mixing time of $200 \mathrm{~s}$.

\section{References}

1. A. Yaraghi, M. Ebrahimi, F. Ein-Mozaffari, A. Lohi, Advanced Powder Technology 29(11), 2693-2706 (2018) https://doi.org/10.1016/j.apt.2018.07.019

2. A. Chupshev, V. Konovalov, M. Fomina, IOP Conf. Series: Journal of Physics 1084, 012010 (2018) https://doi: 10.1088/1742-6596/1084/1/012010

3. M. Ebrahimi, A. Yaraghi, F. Ein-Mozaffari, Powder Technology 332, 158-170 (2018) https://doi.org/10.1016/j.powtec.2018.03.061

4. K.V. Vyakaranam, B.K. Ashokan, J.L. Kokini, Journal of Food Engineering 108(4), 585599 (2012) https://doi.org/10.1016/j.jfoodeng.2010.12.001

5. O. Celik, C. Bonten, AIP Conference Proceedings 2055, 020008 (2019) https://doi.org/10.1063/1.5084809

6. X. Zhu, H. Gao, J., Nongye Gongcheng Xuebao Transactions of the Chinese Society of Agricultural Engineering 34(20), 305-314 (2018) DOI: 10.11975 / j.issn.10026819.2018.20.038

7. D. Dickey, E. Souza, Chemical Processing 66(6), 48-51 https://www.chemicalprocessing.com/articles/2003/take-mixing-to-the-max/

8. S. Soni, L. Sharma, P. Meena, S. Roy, K.D.P. Nigam, Chemical Engineering Science 193, 312-324 (2019) https://doi.org/10.1016/j.ces.2018.09.008 
9. C. Habchi, A. Ghanem, T. Lemenand, D. Della Valle, H. Peerhossaini, Chemical Engineering Research and Design, 298-306 https://doi.org/10.1016/j.cherd.2018.12.010

10. V. Kushnir, N. Gavrilov, S. Kim, Procedia Engineering 150, 1168-1175 (2016) https://DOI: 10.1016/jpropro.2016.07.231

11. I. Emeljanova, A. Anishchenko, O. Dobrokhodova, Preparation Int. J. of Eng. and Technol 7/3, 102 (2018) https://DOI: 10.14419/ijet.v7i3.2.14383

12. A. Chupshev, V. Teryushkov, V. Konovalov, A. Mishanin, V. Novikov, M. Fomina, IOP Conf. Series: Earth and Environmental Science 403, 012102 (2019) https://doi: 10.1088/1755-1315/403/1/012102

13. G. Golub, Y. Myhailovych, O. Achkevych, V. Chuba, Eastern-European Journal of $\begin{array}{llll}\text { Enterprise } & \text { Technologies } & \text { 3(7-99), } & \text { 64-72 }\end{array}$ http://journals.uran.ua/eejet/article/view/166944

14. V. Teryushkov, A. Chupshev, V. Konovalov, Yu. Rodionov, IOP Conf. Series: Journal of Physics: Conf. Series 1278, 012012 (2019) https://doi: 10.1088/17426596/1278/1/012012

15. Yu.T. Selivanov, V.F. Pershin, Theoretical Foundations of Chemical Engineering 1(38), 99-101 (2004) https://doi.org/10.1023/B:TFCE.0000014396.66896.13

16. J.J.Schemmel, T.N. Kolba, M.P. Salguero, M. West, Journal of Testing and Evaluation 46(6), JTE20160514 (2018) https://doi.org/10.1520/JTE20160514

17. L. Li, D. Wang, C. Li, Nongye Jixie Xuebao Transactions of the Chinese Society for Agricultural Machinery 48(8), 123 (2017) DOI: 10.6041/j.issn.1000-1298.2017.08.013

18. L. Li, D. Wang, C. Li, D. Jiang, Z. Ping, Nongye Jixie Xuebao Transactions of the Chinese Society for Agricultural Machinery 48(10), $67 \quad$ (2017) https://DOI: 10.6041/j.issn.1000-1298.2017.10.008

19. C.F. Ferraris, J. Res. Natl. Inst. Stand. Technol 106(2), 391-399 (2001) doi: 10.6028/jres.106.016

20. B. Korobko, GISAP: physics, mathematics and chemistry (GISAP: PMC) 7, 22-24 (2015) http://dx.doi.org/10.18007/gisap:pmc.v0i7.1185 